\title{
PERBANDINGAN PROFIL BIOFARMASETIKA FAST DISINTEGRATING ORAL TABLET DARI KOMPLEKS INKLUSI GLIMEPIRID-BETASIKLODEKSTRIN TERHADAP GLIMEPIRID MURNI
}

\author{
${ }^{1}$ Fitrianti Darusman, ${ }^{2}$ Silviyaturrohmah, ${ }^{3}$ Kiki Loviana \\ 1,2,3 Program Studi Farmasi, Universitas Islam Bandung, Indonesia \\ email:'efit_bien@yahoo.com
}

\begin{abstract}
ABSTRAK
Fast Disintegrating Oral Tablet (FDOT) merupakan pengembangan dari sistem penghantaran sediaan tablet oral yang dimaksudkan agar bahan aktif farmasi dapat segera dilepaskan tanpa menggunakan air minum dan diabsorbsi ke dalam tubuh melalui rongga mulut sehingga lebih mudah ditelan terutama bagi pasien yang mengalami kesulitan menelan obat yang pada akhirnya dapat meningkatkan kepatuhan pasien dalam mengkonsumsi obat. Glimepirid termasuk dalam Biopharmaceutics Classification System (BCS) kelas II yang mempunyai kelarutan rendah dalam air. Pembentukan kompleks inklusi menggunakan senyawa betasiklodekstrin (BCD) untuk meningkatkan sifat kelarutan sekaligus menutup rasa pahit dari glimepirid (GMP). Pada penelitian ini kompleks inklusi GMP-BCD dibuat pada perbandingan mol 1:1, 1:2 dan 2:1 dengan metode solvent evaporation kemudian dikarakterisasi fisika menggunakan metode Differential Scanning Calorimeter (DSC) yang dikonfirmasi dengan Melting Point Apparatus (MPA), Powder X-ray Diffraction (PXRD), Fourier Transform Infrared (FT-IR) serta Scanning Electron Microscopy (SEM). Formulasi FDOT dibuat dalam dua formula yang masing-masing mengandung GMP murni dan GMPBCD sebagai bahan aktif, crospovidone pada konsentrasi yang bervariasi sebagai superdisintegran dan laktosa granular sebagai bahan pengisi, ditabletasi dengan metode kempa langsung. Evaluasi sediaan FDOT meliputi evaluasi umum tablet dan evaluasi khusus FDOT. Berdasarkan hasil karakterisasi fisika terbentuknya kompleks inklusi GMP-BCD pada perbandingan mol 1:2. Optimasi formulasi menghasilkan crospovidone pada konsentrasi 5\% sebagai superdisintegran. Formulasi FDOT yang mengandung GMP-BCD $(1: 2)$ terbukti memiliki rasa yang manis dengan laju disolusi yang lebih tinggi dibandingkan dengan formula FDOT yang mengandung GMP murni, sebagai zat aktif.

Kata Kunci: Glimepirid, kompleks inklusi, betasiklodekstrin, karakterisasi fisika, fast disintegrating oral tablet
\end{abstract}

\begin{abstract}
Fast Disintegrating Oral Tablet (FDOT) is an development of an oral tablet dosage system intended to allow the pharmaceutically active ingredient to be released immediately without the use of drinking water and absorbed into the body through the oral cavity making it easier to swallow, especially for patients who have difficulty swallowing ultimately can improve patient compliance in taking the drug. Glimepiride is included in class II of Biopharmaceutics Classification System (BCS) which has low solubility in water. The inclusion complex has been performed using betacyclodextrin (BCD) compounds to increase the solubility properties as well as to close the bitter taste of glimepiride (GMP). In this study the GMP-BCD inclusion complex was made at 1:1, 1:2 and 2:1 mole ratio with solvent evaporation methods then characterized physics using the Differential Scanning Calorimeter (DSC) method confirmed by the Melting Point Apparatus (MPA), Powder X-ray Diffraction (PXRD), Fourier Transform Infrared (FT-IR) and Scanning Electron Microscopy (SEM).
\end{abstract}


The FDOT formulation is made in two formulas which each contain pure GMP and GMP$\mathrm{BCD}$ as the active ingredient, crospovidone at varying concentrations as superdisintegran and lactose granular as filler material, tableted with the direct compression method. Evaluation of FDOT preparations includes general evaluation of tablets and FDOT-specific evaluations. Based on the results of physics characterization of the formation of the GMPBCD inclusion complex at 1:2 mole ratio. Optimization of the formulation resulted in crospovidone at a concentration of $5 \%$ as superdisintegrant. The FDOT formulation containing GMP-BCD (1:2) are shown to have a sweet taste with higher dissolution rates compared with FDOT formula containing pure GMP, as an active ingredients.

Keywords: Glimepiride, inclusion complexes, betacyclodextrin, physics characterization, fast disintegrating oral tablet

\section{PENDAHULUAN}

Glimepirid (GMP) adalah obat antidiabetik oral dari golongan sulfonilurea generasi ketiga yang mampu menurunkan kadar glukosa darah. GMP memiliki keunggulan penting dibandingkan dengan golongan sulfonilurea lainnya, yaitu dosisnya rendah, onset yang cepat, durasi kerja yang lama dan efek samping hipoglikemia yang kecil (Ammar, 2006). Namun GMP ini termasuk obat dalam Biopharmaceutical Classification Systems (BCS) kelas II yang menunjukkan kecepatan absorbsi gastrointestinal yang lambat. Hal ini disebabkan oleh kelarutan GMP yang praktis tidak larut dalam air dan sangat hidrofobik, yang berpengaruh pada laju disolusi dan bioavailabilitasnya (Sweetman, 2007).

Secara komersial, sediaan obat antidiabetika oral tersedia dalam bentuk tablet oral konvensional yang sudah tentu penggunaannya kurang begitu nyaman bagi golongan pasien usia lanjut yang mayoritas mengidap penyakit diabetes mellitus tipe II ini, sehingga dapat menurunkan kepatuhan pasien dalam mengkonsumsi obatnya, apalagi diharuskan untuk mengkonsumsi obat dalam jangka waktu cukup yang lama. Salah satu strategi untuk mengatasi masalah tersebut adalah melalui pengembangan bentuk sediaan tablet yang digunakan dalam rongga mulut yaitu fast disintegrating oral tablet (FDOT). Sistem penghantaran FDOT dimaksudkan agar bahan aktif farmasi dapat segera dilepaskan tanpa menggunakan air minum dan diabsorbsi ke dalam tubuh melalui rongga mulut. Akan tetapi untuk beberapa bahan aktif farmasi yang memberikan barier untuk pengembangan sediaan ini, seperti GMP, merupakan tantangan yang tidak mudah diatasi yaitu kelarutan yang sangat rendah dan rasa yang tidak menyenangkan (pahit). Oleh karena itu, pada pengembangan sediaan FDOT ini harus memperhatikan teknik tertentu agar dapat mengatasi keterbatasan tersebut (Ammar, 2006).

Pada penelitian ini, dikembangkan teknik kompleks inklusi dengan betasiklodekstrin $(\mathrm{BCD})$ untuk menekan rasa pahit sekaligus berperan meningkatkan kelarutan GMP (Liu, R., 2000). Siklodekstrin merupakan suatu senyawa berbentuk torus 
(rongga) yang mempunyai gugus lipofilik pada bagian dalam rongga dan gugus hidrofilik pada permukaan luarnya. Struktur ini memungkinkan siklodekstrin berinteraksi dengan berbagai molekul membentuk kompleks inklusi secara non kovalen (Challa, et.al.,2005). Di antara golongan siklodekstrin, betasiklodekstrin (BCD) paling banyak digunakan pada pengembangan formula dan sistem penghantaran obat. Oleh karena rasa dan waktu hancur merupakan persyaratan utama yang harus dipenuhi untuk sediaan FDOT, maka dalam proses pengembangannya dilakukan kajian bahan penghancur (superdisintegran) dan pengisi yang paling optimal untuk menghasilkan FDOT GMP yang memenuhi pernyaratan mutu (Rachmawati, 2011).

Berdasarkan latar belakang tersebut maka rumusan masalah dalam penelitian ini adalah menentukan perbandingan mol terbentuknya kompleks inklusi GMP-BCD berdasarkan hasil karakterisasi fisika, optimasi formula FDOT untuk menentukan konsentrasi terbaik crospovidone sebagai superdisintegran, perbandingaan profil FDOT yang mengandung zat aktif kompleks inklusi GMP-BCD (1:2) terhadap FDOT yang mengandung zat aktif GMP murni sebagai bahan aktif berdasarkan hasil evaluasi.

\section{METODE PENELITIAN}

\subsection{Alat}

Timbangan analitik (Mettler Toledo AG204), vortex mixer (JEIO Tech),
Differential Scanning Calorymetri (DSCTGA, STA PT1600, Linseis Thermal Analysis), Melting Point Apparatus (MPA, Stuart), Powder X-Ray Diffraction (PXRD, Bruker D8 Advance), Spektrofotometer Fourier Transform Infrared (FT-IR, Shimadzu), Scanning Electron Microscope (SEM, JSM-6510LV, JEOL USA Inc.), spektofotometer (Shimadzu UVmini-1240), moisture analytical balance (Mettler Toledo), tapped density tester (Electrolab), mesin pencetak tablet single punch (Delta), jangka sorong (Vernier Caliper), hardness tester (Elektric Aspirator), friability abrasion tester (Copley), dissolution tester (Erweka) dan hot plate-magnetic stirrer (Thermo scientific).

\subsection{Bahan}

Glimepirid (Glenmark, India), betasiklodekstrin (Roquette, USA), metanol, aquadest, crosspovidon, laktosa, polivinilpirolidon, magnesium stearat, talk, mentol, etanol, dinatrium hidrogen fosfat dan kalium dihidrogen fosfat. Bahan dan reagen yang digunakan grade pro analisis.

\subsection{Prosedur}

\section{1) Pembuatan Senyawa Kompleks Inklusi GMP-BCD}

Kompleks inklusi GMP dalam BCD dibuat dengan menimbang masing-masing bahan berdasarkan perbandingan mol 1:1, 1:2 dan 2:1 melalui teknik solvent evaporation. Caranya GMP dilarutkan dalam metanol sedangkan BCD dilarutkan dalam aquadest. Keduanya dicampurkan dengan pengadukan 
konstan berkecepatan 500 rpm selama 24 jam.

Campuran ini didiamkan pada suhu kamar untuk menguapkan pelarut hingga diperoleh endapan. Setelah mengering, endapan senyawa kompleks inklusi yang terbentuk diayak dengan ayakan mesh 20, kemudian disimpan di dalam desikator.

\section{2) Karakterisasi Fisika}

Karakterisasi fisika dilakukan terhadap sampel serbuk senyawa kompleks inklusi GMP-BCD pada perbandingan mol 1:1, 1:2 dan 2:1 yang dibandingkan dengan serbuk GMP dan BCD masing-masing dalam kondisi murni serta campuran fisik keduanya, meliputi :

\section{a. Differential Scanning Calorimetry (DSC)}

Sebanyak 5-20 mg sampel diletakkan pada crucible alumina instrumen DSC. Analisis termal dilakukan pada rentang temperatur 32$400^{\circ} \mathrm{C}$ dengan laju pemanasan $10^{\circ} \mathrm{C}$ per menit.

\section{b. Melting Point Apparatus (MPA)}

Sampel dimasukkan ke dalam pipa kapiler lalu diletakkan pada alat MPA. Kemudian alat di setting pada rentang temperatur $30-300^{\circ} \mathrm{C}$ dengan laju pemanasan $10^{\circ} \mathrm{C} /$ menit untuk plateu dan $2^{\circ} \mathrm{C} /$ menit untuk peleburan.

\section{c. Powder X-Ray Diffraction (PXRD)}

Sebanyak 100-200 mg sampel pada sample holder diletakkan di ruang sampel difraktometer sinar-X. Analisis dilakukan pada rentang sudut difraksi $2 \theta \quad 5-40^{\circ}$ menggunakan radiasi $\mathrm{CuK} \alpha(\lambda=1.542 \AA)$ pada $40 \mathrm{kV}$ dan $30 \mathrm{~mA}$.

\section{d. Fourier Transform Infrared (FTIR)}

Sejumlah sampel dibuat pellet dengan kalium bromida yang dikempa dengan tekanan 8-9 ton. Selanjutnya pellet dianalisis pada bilangan gelombang $4000-400 \mathrm{~cm}^{-1}$.

\section{e. Scanning Electron Microscope (SEM)}

Sedikit sampel diletakkan di atas sample holder dan dilapisi gold-palladium dengan auto fine coater. Sampel yang telah terlapisi gold-palladium kemudian diletakkan pada specimen chamber instrumen SEM dan diamati pada komputer untuk difoto pada perbesaran yang sesuai.

\section{3) Formulasi Sediaan FDOT \\ a. Optimasi Formula FDOT}

Pembuatan sediaan FDOT diawali dengan optimasi formula yang memvariasikan crospovidone sebagai superdisintegran dalam beberapa konsentrasi yang ditabletasi secara kempa langsung, dengan bobot $150 \mathrm{mg}$ per tablet.

Tabel 1. Optimasi Superdisintegran Formula FDOT

\begin{tabular}{|l|c|c|c|c|}
\hline \multirow{2}{*}{\multicolumn{1}{|c|}{ Nama Bahan }} & \multicolumn{4}{|c|}{ Komposisi } \\
\cline { 2 - 5 } & $\mathbf{1}$ & $\mathbf{2}$ & $\mathbf{3}$ & $\mathbf{4}$ \\
\hline Crospovidone (\%) & 2 & 3 & 4 & 5 \\
\hline Mg stearat (\%) & 2 & 2 & 2 & 2 \\
\hline Talk (\%) & 2 & 2 & 2 & 2 \\
\hline Mentol (\%) & 0,2 & 0,2 & 0,2 & 0,2 \\
\hline $\begin{array}{l}\text { Laktosa granular } \\
\text { (g) }\end{array}$ & Qs & Qs & Qs & Qs \\
\hline
\end{tabular}




\section{b. Pembuatan FDOT}

Formula hasil optimasi dengan konsentrasi terbaik crospovidone sebagai superdisintegran berdasarkan evaluasi dipilih untuk membuat 2 formula sediaan FDOT yang mengandung zat aktif GMP murni dan GMP dalam kompleks inklusi dengan BCD (1:2) dengan dosis (setara) $5 \mathrm{mg}$.

Tabel 2. Formula FDOT yang Terpilih

\begin{tabular}{|c|c|c|}
\hline \multirow{2}{*}{ Nama Bahan } & \multicolumn{2}{|c|}{ Komposisi Formula } \\
\hline & 1 & 2 \\
\hline $\begin{array}{l}\text { Kompleks inklusi } \\
\text { GMP-BCD }(1: 2)(\mathrm{mg})\end{array}$ & - & 28,134 \\
\hline Glimepirid (mg) & 5 & - \\
\hline Crospovidone (\%) & $?$ & $?$ \\
\hline Mg stearat (\%) & 2 & 2 \\
\hline Talk (\%) & 2 & 2 \\
\hline Mentol (\%) & 0,2 & 0,2 \\
\hline Laktosa granular (g) & Qs & Qs \\
\hline
\end{tabular}

\section{c. Evaluasi FDOT}

\section{Evaluasi Massa Kempa}

Evaluasi massa kempa meliputi pengukuran kandungan lembab, sifat aliran dan kerapatan (Rachmawati, 2011).

\section{Evaluasi Sediaan Akhir}

Evaluasi sediaan akhir meliputi evaluasi umum yakni organoleptik, keseragaman ukuran, kekerasan, friabilitas/friksibilitas, keragaman bobot, keseragaman kandungan dan laju disolusi, sedangkan evaluasi khusus yakni waktu pembasahan dan rasio absorbsi air serta waktu hancur (Rachmawati, 2011).

\section{HASIL DAN PEMBAHASAN}

\subsection{Pembuatan Senyawa Kompleks Inklusi GMP-BCD}

Padatan senyawa kompleks inklusi GMP-BCD dibuat berdasarkan perbandingan mol 1:2 yang diperhitungkan dari berat molekul masing-masing, yaitu GMP 490,62 g/mol dan BCD $1135 \mathrm{~g} / \mathrm{mol}$ dengan teknik solvent evaporation. Pada teknik ini, peluang terbentuknya kompleks inklusi cukup signifkan disebabkan adanya proses pelarutan secara molekular yang terjadi pada masingmasing molekul guest dan molekul host dalam pelarutnya sebelum dilakukan pencampuran sehingga memungkinkan terjadinya interaksi kompleks inklusi antara GMP dengan BCD.

\subsection{Karakterisasi Fisika}

\section{a. Differential Scanning Calorimetry (DSC)}

Karakterisasi fisika menggunakan metode DSC untuk mengidentifikasi perubahan termodinamika dari serbuk kompleks inklusi GMP-BCD yang dibandingkan dengan serbuk GMP tunggal, BCD tunggal dan campuran fisik keduanya pada saat dipanaskan yang ditunjukkan dengan puncak endotermik dan eksotermik. Data hasil karakterisasi fisika DSC terdapat pada Gambar 1. 

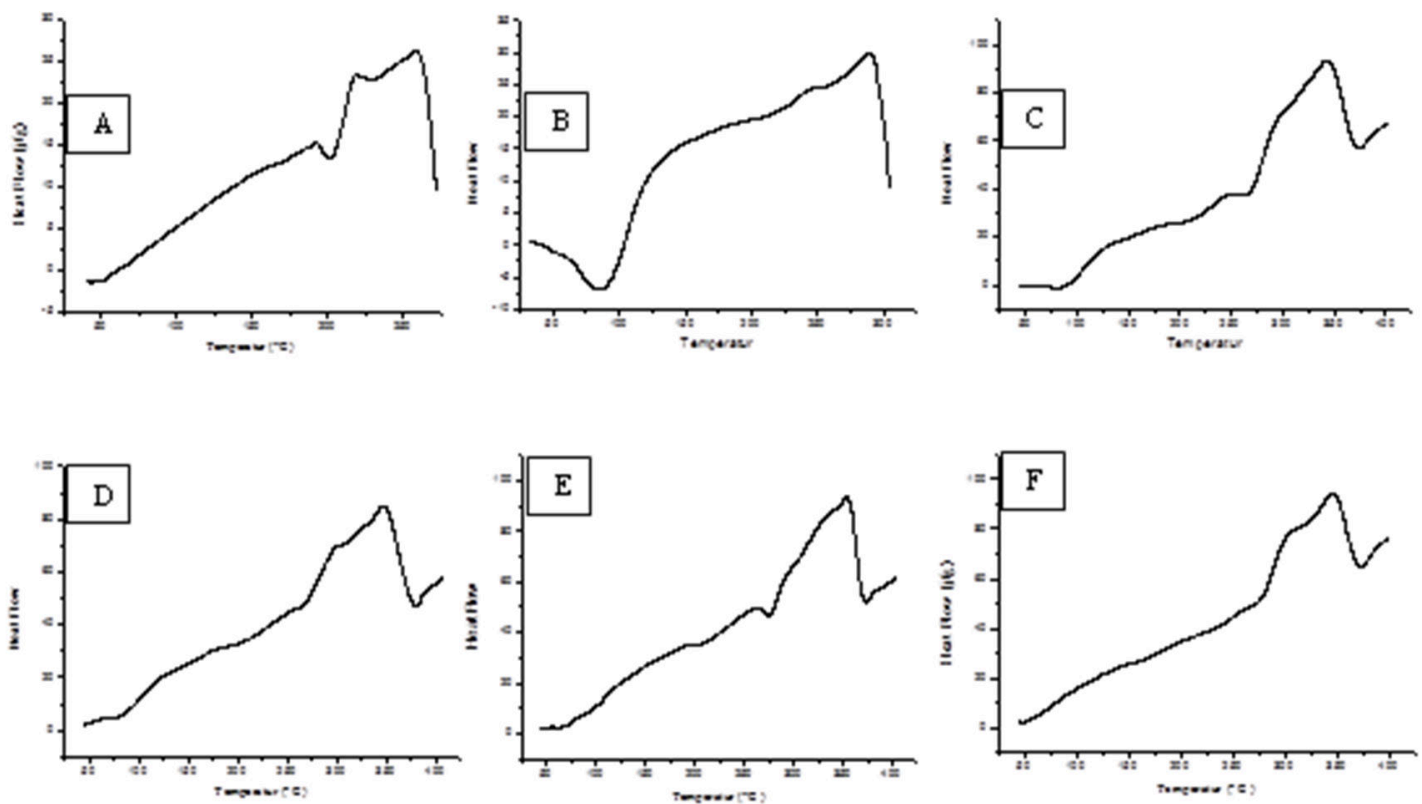

Gambar 1 Termogram DSC serbuk: A. GMP, B. BCD, C. Campuran fisika GMP-BCD, D. Kompleks inklusi GMP-BCD (1:1), E. Kompleks inklusi GMP-BCD (1:2), F. Kompleks inklusi GMP-BCD $(2: 1)$

\section{b. Melting Point Apparatus (MPA)}

BCD tunggal dan campuran fisik keduanya Karakterisasi menggunakan MPA pada saat dipanaskan yang ditunjukkan untuk mengidentifikasi profil termal dari serbuk kompleks inklusi GMP-BCD yang dibandingkan dengan serbuk GMP tunggal, menggunakan MPA terdapat pada Tabel 3. 
Perbandingan Profil Biofarmasetika....

Tabel 3 Profil Termal menggunakan MPA

\begin{tabular}{|c|c|c|}
\hline Sampel & Titik Leleh & Keterangan \\
\hline GMP & $209-211^{\circ} \mathrm{C}$ & Mulai terjadi pelelehan pada suhu $209-211^{\circ} \mathrm{C}$ s ampai melebur sempuma pada suhu $211^{\circ} \mathrm{C}$ \\
\hline $\mathrm{BCD}$ & $260-280^{\circ} \mathrm{C}$ & $\begin{array}{l}\text { Terjadi pelepas an uap air pada suhu } 155^{\circ} \mathrm{C} \\
\text { Mulai terjadi perubahan menjadi wama kuning pada suhu } 260^{\circ} \mathrm{C} \\
\text { Terjadi perubahan wama kuning menjadi wama coklat (karamelis asi) pada suhu } 280^{\circ} \mathrm{C}\end{array}$ \\
\hline CF & $211-280^{\circ} \mathrm{C}$ & $\begin{array}{l}\text { Terjadi pelepas an uap air pada suhu } 155^{\circ} \mathrm{C} \\
\text { Mulai terjadi perubahan menjadi wama kuning pada suhu } 211^{\circ} \mathrm{C} \\
\text { Terjadi perubahan wama kuning menjadi wama coklat (karamelis asi) pada suhu } 280^{\circ} \mathrm{C}\end{array}$ \\
\hline SE 1:1 & $240-280^{\circ} \mathrm{C}$ & $\begin{array}{l}\text { Terjadi pelepas an uap air pada suhu } 155^{\circ} \mathrm{C} \\
\text { Mulai terjadi perubahan menjadi wama kuning pada suhu } 240^{\circ} \mathrm{C} \\
\text { Terjadi perubahan wama kuning menjadi wama coklat (karamelis asi) pada suhu } 280^{\circ} \mathrm{C}\end{array}$ \\
\hline SE 1:2 & $250-280^{\circ} \mathrm{C}$ & $\begin{array}{l}\text { Terjadi pelepas an uap air pada suhu } 155^{\circ} \mathrm{C} \\
\text { Mulai terjadi perubahan menjadi wama kuning pada suhu } 250^{\circ} \mathrm{C} \\
\text { Terjadi perubahan wama kuning menjadi wama coklat (karamelisasi) pada suhu } 280^{\circ} \mathrm{C}\end{array}$ \\
\hline SE $2: 1$ & $238-280^{\circ} \mathrm{C}$ & $\begin{array}{l}\text { Terjadi pelepas an uap air pada suhu } 155^{\circ} \mathrm{C} \\
\text { Mulai terjadi perubahan menjadi wama kuning pada suhu } 238^{\circ} \mathrm{C} \\
\text { Terjadi perubahan wama kuning menjadi wama coklat (karamelis asi) pada suhu } 280^{\circ} \mathrm{C}\end{array}$ \\
\hline
\end{tabular}

Keterangan :

GMP (Glimepirid), BCD (Betasiklodekstrin), CF (Campuran Fisika), KI (Kompleks Inklusi).

\section{c. Powder X-Ray Diffraction (PXRD)}

Karakterisasi sifat kristalinitas menggunakan metoda PXRD untuk mengidentifikasi pola difraksi pada difraktogram dari kompleks inklusi GMPBCD, GMP tunggal, BCD tunggal dan campuran fisik keduanya yang terdapat pada

Gambar 2. Dari difraktogram dapat menilai keberhasilan terbentuknya kompleks inklusi host-guest dengan membandingkan pola difraksi terhadap pola difraksi host.

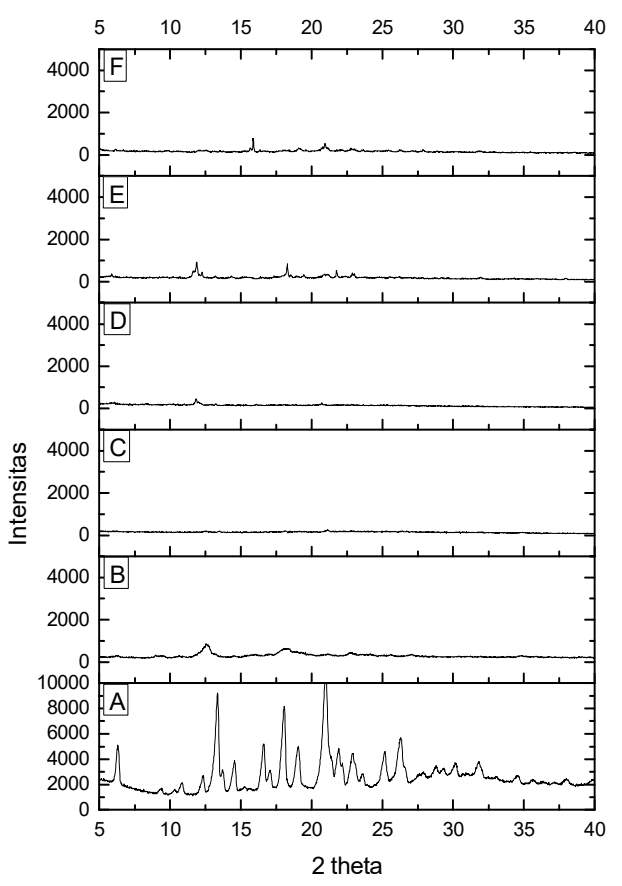

Gambar 2. Difraktogram sinar-X serbuk : A.

GMP, B. BCD, C. Campuran fisika GMPBCD, D. Kompleks inklusi GMP-BCD (1:1), E. Kompleks inklusi GMP-BCD (1:2), F. Kompleks inklusi GMP-BCD (2:1) 


\section{d. Fourier Transform Infrared (FTIR)}

Karakterisasi fisika menggunakan metoda FTIR untuk mengidentifikasi pita serapan pada bilangan gelombang tertentu yang menggambarkan gugus fungsi dari kompleks inklusi GMP-BCD, GMP tunggal, BCD tunggal dan campuran fisik keduanya yang terdapat pada Gambar 3. Dari spektrum FTIR dapat menilai keberhasilan terbentuknya kompleks inklusi host-guest dengan membandingkan terhadap pita-pita yang menggambarkan gugus fungsional dari molekul host.

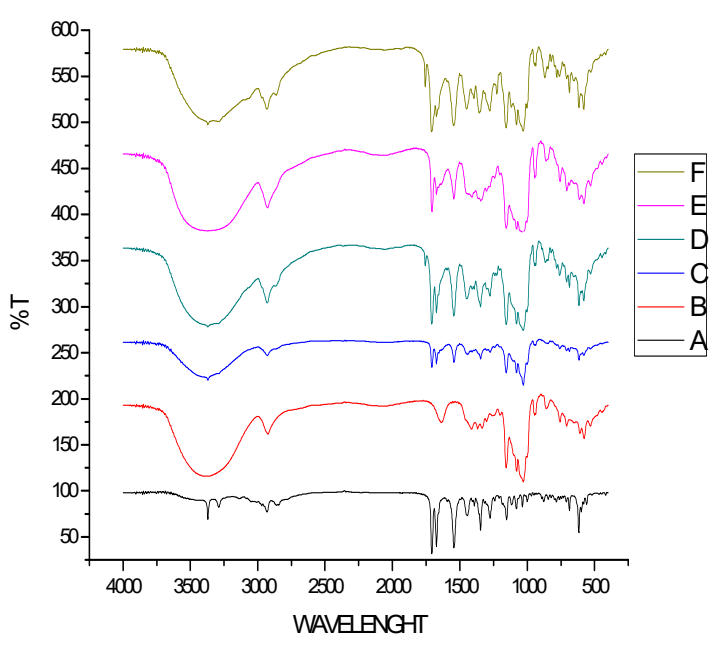

Gambar 3 Spektrum FTIR serbuk : A. GMP, B. BCD, C. Campuran fisika GMP-BCD, D. Kompleks inklusi GMP-BCD (1:1), E. Kompleks inklusi GMP-BCD (1:2), F. Kompleks inklusi GMP-BCD (2:1).

\section{e. Scanning Electron Microscope (SEM)}

Karakterisasi fisika menggunakan metoda SEM untuk mengetahui morfologi permukaan bahan dari kompleks inklusi GMP-BCD, GMP tunggal, BCD tunggal dan

Gambar 4. Dari mikrofoto SEM dapat menilai keberhasilan terbentuknya kompleks inklusi host-guest dengan membandingkan mikrofoto SEM terhadap mikrofoto SEM campuran fisik.
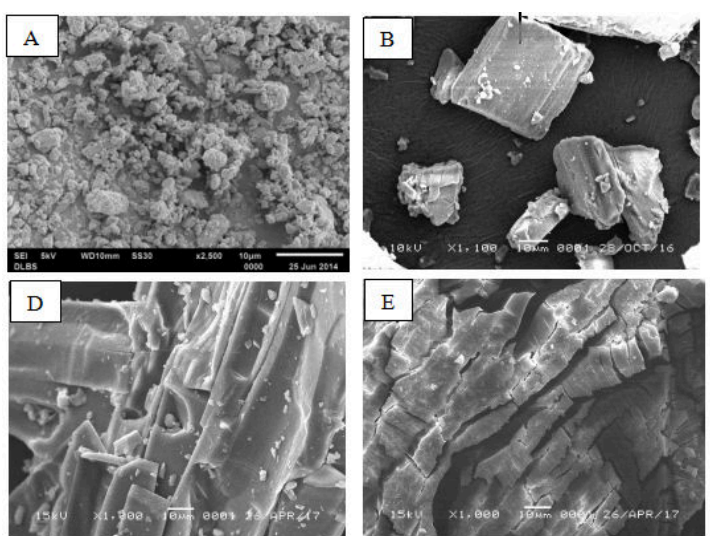

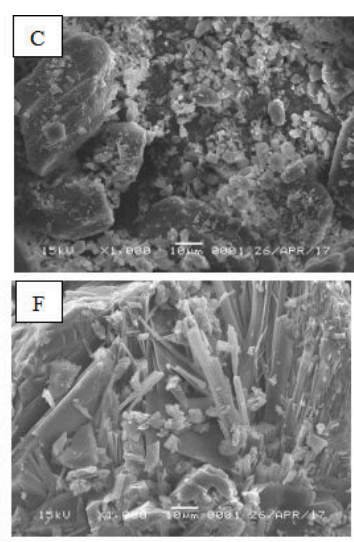

Gambar 4 Mikrofoto SEM serbuk : A. GMP, B. BCD, C. Campuran fisika GMP-BCD, D. Kompleks inklusi GMP-BCD (1:1), E. Kompleks inklusi GMP-BCD (1:2), F. Kompleks inklusi GMP-BCD (2:1). 


\subsection{Formulasi Sediaan FDOT}

\section{a. Optimasi Formula FDOT}

Dilakukan dengan memvariasikan konsentrasi crospovidone sebagai superdisintegran. Crospovidone mempunyai bentuk partikel berpori yang mudah menyerap air melalui aksi kapiler sehingga mudah terbasahi dan cepat hancur. dengan konsentrasi crospovidone 5\%.
Pembuatan FDOT dilakukan dengan metode kempa langsung bertujuan untuk mencegah kemungkinan terjadinya ketidakstabilan dan pemisahan kembali GMP dari kompleks inklusi. Dari hasil evaluasi optimasi formula FDOT, dapat ditentukan formulasi superdisintegran terbaik yaitu formula 4

Tabel 4 Evaluasi Optimasi Formulasi FDOT

\begin{tabular}{|c|c|c|c|c|c|}
\hline No & Evaluasi & $\begin{array}{c}\text { Formula } 1 \\
\text { (crospovidone 2\%) }\end{array}$ & $\begin{array}{c}\text { Formula } 2 \\
\text { (crospovidone 3\%) }\end{array}$ & $\begin{array}{c}\text { Formula } 3 \\
\text { (crospovidone 4\%) }\end{array}$ & $\begin{array}{c}\text { Formula } 4 \\
\text { (crospovidone 5\%) }\end{array}$ \\
\hline \multirow[t]{5}{*}{1.} & Organoleptis & & & & \\
\hline & Bentuk & Bulat & Bulat & Bulat & Bulat \\
\hline & $\mathrm{Bau}$ & Khas (mentol) & Khas (mentol) & Khas (mentol) & Khas (mentol) \\
\hline & Warna & Putih & Putih & Putih & Putih \\
\hline & Rasa & Manis & Manis & Manis & Manis \\
\hline 2. & $\begin{array}{l}\text { Keseragaman ukuran } \\
(\mathrm{cm})\end{array}$ & $0,8 \pm 0,28$ & $0,8 \pm 0,28$ & $0,8 \pm 0,28$ & $0,8 \pm 0,28$ \\
\hline 3. & Kekerasan (kg/ $\left.\mathrm{cm}^{2}\right)$ & $3,9 \pm 0,819$ & $3,35 \pm 0,401$ & $3,1 \pm 0,447$ & $3 \pm 0,343$ \\
\hline \multirow[t]{2}{*}{4.} & Friabilitas (\%) & 0,455 & 0,480 & 0,673 & 0,682 \\
\hline & Friksibilitas (\%) & 0,493 & 0,518 & 0,942 & 1,013 \\
\hline 5. & Keragaman bobot (mg) & $154,05 \pm 1,905$ & $152,2 \pm 1,436$ & $150,85 \pm 0,813$ & $150 \pm 2,248$ \\
\hline \multirow[t]{2}{*}{6.} & $\begin{array}{c}\text { Waktu pembasahan } \\
\text { (detik) }\end{array}$ & 31,397 & 29,815 & 28,422 & 24,90 \\
\hline & Rasio penyerapan (\%) & 21,756 & 28,790 & 29,036 & 32,624 \\
\hline 7. & Waktu hancur (detik) & 31,853 & 29,185 & 18,83 & 18,598 \\
\hline
\end{tabular}

\section{b. Pembuatan FDOT}

Setelah mendapatkan formula terbaik dari hasil optimasi, maka dibuat 2 formula FDOT. Formula 1 adalah FDOT yang 
c. Evaluasi FDOT

1) Evaluasi Massa Kempa

Tabel 5. Evaluasi Massa Kempa

\begin{tabular}{|c|c|c|}
\hline Exaluasi & $\begin{array}{c}\text { Formula I } \\
\text { (Zat Aktif GMP murni) }\end{array}$ & $\begin{array}{c}\text { Formula II } \\
\text { (Zat Aktif Kompleks } \\
\text { Inklusi GMP-BCD } 1: 2 \text { ) }\end{array}$ \\
\hline 1. Kelembaban (\%) & 1,78 & 2,14 \\
\hline $\begin{array}{l}\text { 2. Kecepatan Alir } \\
\text { (gram/detik) }\end{array}$ & $30 / 2,23$ & $30 / 3,34$ \\
\hline 3. Sudut Baring $\left(^{\circ}\right)$ & 17,797 & 20,506 \\
\hline \multicolumn{3}{|l|}{ 4. Uji densitas } \\
\hline a. Bj Nyata $(\mathrm{g} / \mathrm{ml})$ & 0,476 & 0,490 \\
\hline b. $\underset{\substack{\mathrm{Bj} \\
(\mathrm{g} / \mathrm{ml})}}{ }$ Mampat & 0,568 & 0,581 \\
\hline c. Bj Sejati $(\mathrm{g} / \mathrm{ml})$ & 1,281 & 1,451 \\
\hline $\begin{array}{ll}\text { d. } & \text { Kadar } \\
& \text { Pemampatan } \\
& (\%)\end{array}$ & 16,191 & 15,686 \\
\hline e. Rasio Hausner & 1,193 & 1,186 \\
\hline $\begin{array}{l}\text { f. Kompresibilitas } \\
(\%)\end{array}$ & 16,197 & 15,663 \\
\hline
\end{tabular}

2) Evaluasi Sediaan Akhir

Tabel 6. Evaluasi Sediaan Akhir Umum FDOT

\begin{tabular}{|c|c|c|c|}
\hline No & Evaluasi & $\begin{array}{c}\text { Formula } 1 \\
\text { (Zat Aktif GMP murni) }\end{array}$ & $\begin{array}{c}\text { Formula } 2 \\
\text { (Zat Aktif Kompleks } \\
\text { Inblusi GMP-BCD } 1 \text { : } \\
\text { 2) }\end{array}$ \\
\hline \multirow[t]{5}{*}{1.} & Organoleptis & & \\
\hline & Bentuk & $\begin{array}{c}\text { Bulat dengan garis pada } \\
\text { permukaan tablet }\end{array}$ & $\begin{array}{c}\text { Bulat dengan garis pada } \\
\text { permukaan tablet }\end{array}$ \\
\hline & & Khas (mentol) & Khas (mentol) \\
\hline & Вau & Butih & Putih \\
\hline & $\begin{array}{l}\text { Warna } \\
\text { Rasa }\end{array}$ & Sedikit manis & Manis. \\
\hline 2. & Keseragaman ukuran (cm) & $\begin{array}{c}\text { Diameter } 0,61 \pm 0 \\
\text { Tebal } 0,32 \pm 0\end{array}$ & $\begin{array}{c}\text { Diameter } 0,61 \pm 0 \\
\text { Tebal } 0,32 \pm 0\end{array}$ \\
\hline 3. & Kekerasan $\left(\mathrm{kg} / \mathrm{cm}^{2}\right)$ & $4,575 \pm 0,438$ & $4,25 \pm 0,659$ \\
\hline \multirow[t]{2}{*}{4.} & Friabilitas (\%) & 0,325 & 0,435 \\
\hline & Friksibilitas (\%) & 0,098 & 0,227 \\
\hline \multirow[t]{2}{*}{5.} & Keseragaman sediaan & & \\
\hline & $\begin{array}{l}\text { a. Keragaman bobot } \\
\text { (mg) } \\
\text { b. Keseragaman } \\
\text { kandungan }\end{array}$ & $\begin{array}{c}151,415 \pm 1,480 \\
86,49 \pm 1,238\end{array}$ & $\begin{array}{l}150,91 \pm 0,882 \\
86,155 \pm 1,495\end{array}$ \\
\hline
\end{tabular}




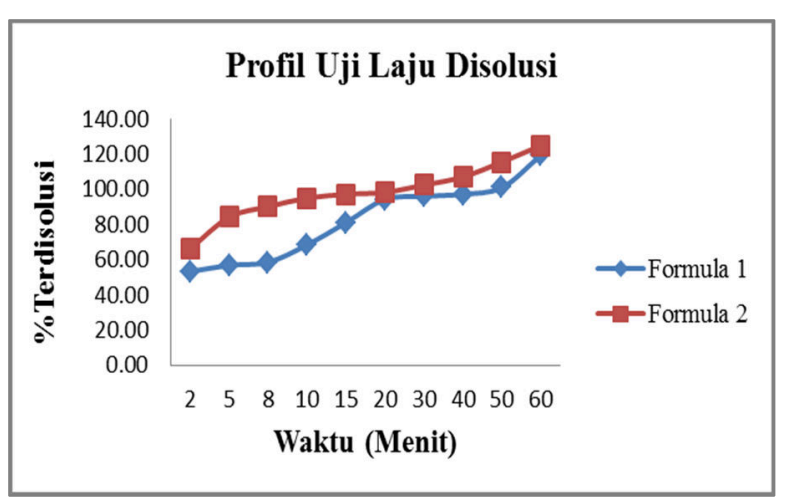

Gambar 5 Profil Uji Laju Disolusi FDOT : Formula 1 = FDOT dengan zat aktif GMP murni Formula 2 =FDOT dengan zat aktif kompleks inklusi GMP-BCD (1:2)

Tabel 7. Evaluasi sediaan akhir Khusus FDOT

\begin{tabular}{|c|l|c|c|}
\hline No & Evaluasi & $\begin{array}{c}\text { Formula } \\
\mathbf{1} \\
\text { (Zat } \\
\text { Aktif } \\
\text { GMP } \\
\text { murni) }\end{array}$ & $\begin{array}{c}\text { Formula 2 } \\
\text { (Zat Aktif } \\
\text { Kompleks } \\
\text { Inklusi } \\
\text { GMP-BCD } \\
\mathbf{1 ~ : ~ 2 ) ~}\end{array}$ \\
\hline \multirow{2}{*}{ 1. } & $\begin{array}{l}\text { Waktu } \\
\text { pembasahan } \\
\text { (detik) }\end{array}$ & 42,848 & 37,373 \\
\cline { 2 - 4 } & $\begin{array}{l}\text { Rasio } \\
\text { penyerapan } \\
\text { (\%) }\end{array}$ & $27,076 \%$ & $32,085 \%$ \\
\hline \multirow{2}{*}{ 2. } & $\begin{array}{l}\text { Waktu } \\
\text { hancur } \\
\text { (detik) }\end{array}$ & 16,08 & 8,73 \\
\hline
\end{tabular}

Dari hasil evaluasi sediaan akhir umum maupun khusus, formula FDOT dengan crospovidone konsentrasi $5 \%$ sebagai superdisintegran yang memgandung serbuk kompleks inklusi GMP-BCD (1:2) sebagai aktif terbukti memiliki rasa manis, waktu pembasahan yang cepat, waktu hancur yang cepat dan laju disolusi yang tinggi dibandingkan dengan formula FDOT yang mengandung zat aktif serbuk GMP murni.

\section{KESIMPULAN DAN SARAN}

Hasil karakterisasi fisika menunjukkan terbentuknya kompleks inklusi GMP-BCD pada perbandingan mol 1:2. Hasil evaluasi optimasi formula FDOT menunjukkan konsentrasi terbaik crospovidone sebagai superdisintegran pada 5\%. Hasil evaluasi sediaan akhir, Formula FDOT yang mengandung zat aktif kompleks inklusi GMP-BCD (1:2) terbukti memiliki rasa yang manis, waktu pembasahan yang cepat, waktu hancur yang cepat dan laju disolusi yang lebih tinggi dibandingkan dengan formula FDOT yang mengandung zat aktif GMP murni.

\section{UCAPAN TERIMA KASIH}

Penulis mengucapkan terima kasih kepada LPPM Universitas Islam Bandung atas hibah penelitian yang diperoleh pada periode 2016-2017.

\section{DAFTAR PUSTAKA}

Challa R., Ahuja A., Ali J., Khar RK., 2005. Cyclodextrins in Drug Delivery: An Update Review. AAPS PharmSciTech. 6 (2) Article 43: E329-E357.

Ammar HO., Salama HA., Ghorab M., Mahmoud A., 2006. Formulation and Biological Evaluation of Glimepiride-CyclodextrinPolymer Systems, Int. J. Pharm. 309, 129138.

Liu R., 2000. Water Insoluble Drug Formulation, Taylor and Francis Group, Boca raton, London, New York, 493-517

Sweetman S.C., 2007. Martindale, The Complete Drug Reference, $35^{\text {th }}$ Ed., Pharmaceutical Press, London, Chicago, 399-400

Rachmawati H., Marbun JE., Pamudji SJ., 2011. Pengembangan formula tablet hancur cepat dari kompleks inklusi ketoprofen dalam beta siklodekstrin, Sekolah Farmasi Institut Teknologi Bandung. 